\title{
Why Is Case Management Effective? A Realist Evaluation of Case Management for Frail, Community-Dwelling Older People: Lessons Learned from Belgium
}

\author{
Thérèse Van Durme ${ }^{1}$, Olivier Schmitz ${ }^{1}$, Sophie Cès ${ }^{1}$, Anne-Sophie Lambert ${ }^{1}$, Jenny Billings ${ }^{2}$, \\ Sibyl Anthierens ${ }^{3}$, Maja Lopez-Hartmann³, Roy Remmen ${ }^{3}$, Johanna De Almeida Mello4, \\ Anja Declercq ${ }^{4}$, Jean Macq ${ }^{1}$
}

${ }^{1}$ Institute of Health and Society, Université catholique de Louvain, Brussels, Belgium

${ }^{2}$ Centre for Health Service Studies, University of Kent, Canterbury, UK

${ }^{3}$ Department of General Practice, University of Antwerp, Antwerp, Belgium

${ }^{4}$ LUCAS, KULeuven, Leuven, Belgium

Email: therese.vandurme@uclouvain.be

How to cite this paper: Van Durme, T., Schmitz, O., Cès, S., Lambert, A.-S., Billings, J., Anthierens, S., Lopez-Hartmann, M., Remmen, R., De Almeida Mello, J., Declercq, A. and Macq, J. (2016) Why Is Case Management Effective? A Realist Evaluation of Case Management for Frail, Community-Dwelling Older People: Lessons Learned from Belgium. Open Journal of Nursing, 6, 863-880.

http://dx.doi.org/10.4236/ojn.2016.610085

Received: September 27, 2016

Accepted: October 25, 2016

Published: October 28, 2016

Copyright $\odot 2016$ by authors and

Scientific Research Publishing Inc.

This work is licensed under the Creative

Commons Attribution International

License (CC BY 4.0).

http://creativecommons.org/licenses/by/4.0/

\begin{abstract}
Despite many attempts to evaluate the effectiveness of case management for frail older people, systematic reviews including experimental designs show inconsistent results. Starting from the view that case management is a complex intervention occurring in multilayered realities, we conducted a realist evaluation of case management in Belgium, where this type of intervention is new. Realist approaches are particularly well suited to evaluate complex interventions as they seek to investigate iteratively the literature and empirical data to uncover mid-range theories underpinning the intervention under study. As such, realist evaluations are works in progress which provide tools to describe how, why and for whom an intervention is supposed to work. In this paper, we describe two mid-range theories that can explain why case management can help frail older people to remain at home, through the lens of capacity and social support.
\end{abstract}

\section{Keywords}

Realist Evaluation, Frail Older People, Case Management, Home Care

\section{Introduction}

Frail older people often have complex care needs, especially when frailty is the result of 
the co-existence of two or more chronic conditions [1] and involves receiving care from different healthcare professionals such as general practitioners, home care organisations (nurses, nurse assistants, social workers) and medical specialists. During exacerbations of their condition or new diagnoses, additional involvement of emergency care and other specialisms may be needed [2]. Allowing older people to stay at home has become a universal aim of health and social care agencies across the Western world, to address the combined factors of growing numbers of frail older people and the strain on the health care budgets. Agencies are tackling these problems through the drive for innovative approaches to care. To overcome this fragmentation, the concept of integration of care has been widely "reintroduced" and is central to health and social care policy in many countries [3]. This in itself has introduced more layers of complexity, as there are many ways of defining, explaining or implementing the concept through frameworks. For example, several definitions of integrated care exist, from an operational perspective through to a more person-centred approach. Taking the person perspective, it is widely agreed that this should be at the heart of any discussion about integrated care [4]. Achieving integrated care requires that those involved with planning and providing services should "impose the patient's perspective as the organising principle of service delivery" [5]. National Voices (2013) offer user-based definitions of integrated care such as "My care is planned with people who work together to understand me and my carer(s), put me in control, co-ordinate and delivery services to achieve my best outcomes" that not only serve to create a better understanding between service providers and users of integrated care, but are increasingly being used as outcome measures [6].

When it comes to frameworks and theoretical underpinnings, integrated care has synergy with the chronic care model [7]. This model focuses on six major requirements needed to provide integrated care for people living with chronic conditions, i.e. a tailored system redesign, an appropriate workforce, an appropriate budget and financial incentives, processes to support quality of care, knowledge management and decision support, and clinical information tools. In addition, Vlayen et al. [8] put forward notions of high-quality care which encompass seven dimensions: safety, clinical effectiveness, patient centeredness, timeliness, equity of care, efficiency of care and finally, continuity and service integration. Caring for the frail population in itself enhances the opportunity for continuity and service integration to happen because of the fragmentation of care. Such frameworks have however failed to connect to integrated care delivery in a meaningful and pragmatic way creating a gap between theory and practice [9].

A further consideration is the method of care delivery, and how the service should best be configured to deal with small numbers of frail older people who have a very high level of complex care needs where regular care by the primary care team may not be adequate. Case management is suggested to be an important means to help to achieve integrated care to help this population to remain in better health and, if possible, at home [10]. Case management is defined by the Case Management Society of America ([11], p. 10) as "a collaborative process of assessment, planning, facilitation, care coordination, evaluation, and advocacy for options and services to meet an 
indilvidual's and family's comprehensive health needs through communication and available resources to promote quality, cost-effective outcomes". Case management is brought about in highly diverse ways according to its intensity (frequency and duration of the contacts), its embeddedness in the local care network, the profile and training of the case managers (e.g. nurse-led case management versus social worker-led case management) working either alone or in a team, benefiting or not from reflexive group meetings with peers or supervisions, the inclusion criteria or triggers to identify the population likely to benefit from case management (prompted by routinely collected data or on request of the care provider, the informal caregiver or the beneficiary himself) [12].

However, evidence of the effectiveness of case management for frail older people is hard to establish. Hard outcomes may encompass, among others, delay of institutionalisation, impact on the number of emergency room visits, healthcare consumption, mortality rates, etc. while the impact on so-called "soft", patient-reported outcomes include, for instance, satisfaction or perception of coordination of care [13]. In other words, case management is more likely to have an impact on better quality of care as a process as this is conducive to better outcomes and, at the same time "hard outcomes" are more likely to be influenced in this population by determinants which are not related to the quality of care, such as the negative interactions within long-term illnesses and treatments [14].

It is also important to highlight that because of the high level of interaction between community-dwelling frail older people and their informal caregivers, they are considered here as a dyad [15]. This is the reason why in most instances case managers' interventions will target the dyad instead of each one of them separately, thus making this a more holistic form of care provision.

Because of the heterogeneity of case management's characteristics and interacting contextual components, traditional evaluation designs are ill-suited to evaluate the effectiveness of this type of complex intervention [12] [16]. A realist evaluation may help to respond to our research question, which was to understand the how and why of the effectiveness of case management, and shed light on specific conditions and why approaches with case management could be effective in health care. The main focus will therefore be about the development of mid-range theory to create explanations for these research questions with the help of empirical data gathered in Belgium.

\section{Methods}

A realist approach was used to evaluate the effectiveness of case management in the Belgian context. Described by Pawson and Tilley in 1997 [17] realist evaluations are particularly useful for the evaluation of complex interventions because they take into account the interactions between an intervention and its context. Indeed, case management can be seen as a complex intervention occurring within a complex system because multiple, interacting agents are involved. These agents interact with their environment and these interactions are non-linear and interdependent. In the community 
and the home care setting variables may not be easily controlled and during an intervention many interactions make standardisation not possible. Without central control, emergent behaviours can be observed and the information about the interactions is assimilated by the agents. Finally, as the system evolves over time the partners in care processes learn and evolve. The health system may be expected to improve as a result of this process [18].

The epistemological stance of realist evaluations is rooted in critical realism [19]. Although realists acknowledge an "objective" reality existing outside of the observer, there is a certain level of interaction with the observer (so-called recursivity). This means the interpretation of reality is moderated by the observer. Moreover, the focus lays on mechanisms, which are contextualised, i.e. mechanisms are only triggered under specific conditions or in specific contexts and lead to specific outcomes. Mechanisms are the causal forces, powers, processes or interactions that generate change, combining the use of resources and reasoning that people make [20]. The overall aim of a realist evaluation is to come up with an explanatory mid-range theory about the effectiveness of an intervention, in order to allow theoretical replication.

Typically, a realist evaluation of an intervention starts with the identification of the logic of the intervention (also called programme theory). This seeks to describe the logical link between the objective of an intervention, the resources used, the activities carried out and the expected results. Second, CMOC (Context-Mechanisms-Outcomes Configurations) are looked for, in order to identify underlying mechanisms explaining why a specific outcome was achieved in a specific context. This can be seen as a mid-range theory. Third, candidate mid-range theories are searched in the literature, amongst experts and researchers in order to provide an explanatory framework for these CMOC. Fourthly, adjudication between rival theories or refining of existing theories is done through testing them with the empirical data and iterative consultation of the literature and with experts [21].

Case study design was also employed alongside this realist evaluation approach. These two methodological stances have much synergy and potential in studies of this kind (George and Bennett 2005), an aspect explained further below.

We followed the recommendations of the RAMESES II project for the reporting of realist evaluations [22].

\subsection{Bottom up Projects in Belgium: Setting and First Steps for the Realist Evaluation}

The National Institute of Health and Disability Insurance (NIHDI) created funding in Belgium to identify which alternative interventions of care or support of care were the most effective to maintain frail older people at home at a reasonable cost. This prompted a large-scale programme implementation and evaluation. Amongst other pilot projects, 22 new bottom-up designed case management projects started in April 2010. They were selected by the NIHDI and were financed over four years. Inclusion criteria for the older people to benefit from these projects were defined by Royal Decree (7 July 2009): to be aged 60 or more, living at home, being frail and willing to participate in the scien- 
tific evaluation of the pilot projects. Frailty was defined as (1) to have a score of six or over on the Edmonton Frail Scale [23] or (2) to be dependent for ADL or IADL, as defined by a Katz lump sum [24] or (3) to have a diagnosis of dementia made by a neurologist, geriatrician or psychiatrist. Moreover, care providers of the projects should assess whether the person was likely to benefit from case management during a baseline interview, i.e. have a sufficient level of complex care needs. A consortium of four universities (Université catholique de Louvain, KULeuven, UAntwerpen and Université de Liège) was asked to evaluate the cost benefits and effectiveness of these projects as a programme evaluation.

The protocol describing the overall design of this evaluation has been described previously [25]. Six researchers were involved in this part of the evaluation. The data collection relied mainly on project data, which were collected during four years and comprised official documents, such as the submission files of the projects, administrative databases from NIHDI, websites, yearly questionnaires about the organisational functioning, adaptation strategies for the implementation and embeddedness of the projects. This data collection was completed by yearly interviews with the coordinators and case managers of the projects. Because of the number of researchers involved, an audit trail was agreed upon and followed, in order to ensure the similarity of the data collection and first descriptive analyses. The process was discussed and refined during iterative group sessions amongst researchers. Moreover, to be sure that the results would be useful for the civil servants of the NIHDI, they were also involved repeatedly in the discussion. This helped to define the breadth and depth of the analysis within the given timeframe.

\subsection{First Step: Description of the Logic of the Interventions}

As recommended by Wong et al. [26] [27], we chose to start from the outcomes to describe the logic of case management. These outcomes should reflect meaningful results for the older people and, in some cases, their informal caregiver. Therefore, we chose to use I-Statements as a starting point. I-Statements are patient-reported outcomes and reflect the users' perspective about coordinated care: "My care is planned with people who work together to understand me and my carer(s), put me in control, co-ordinate and deliver services to achieve my best outcomes" and reflect a nationwide commitment in the UK to let the users' perspective guide the quality improvement strategies in this country [6].

\subsection{Second Step: Confrontation with the Empirical Data}

Some authors, such as George and Bennett strongly advise the use of realist approaches in case studies [28]. At the interplay of both approaches lays the focus on looking extensively for causal pathways between phenomena. In case study terms, this is called process tracing, i.e. looking for causal chains, to uncover evidence of causal mechanisms at work or to explain outcomes. In realistic terms, this can be phrased as "causal mechanisms are central to causal explanation" [29]. Process-tracing is therefore an opera- 
tional procedure for attempting to identify and verify the observable within-case implications of causal mechanisms [30]. At an epistemological level, the two approaches share the view that social facts exist independently of the observer and can be the subject of defensible causal inferences [28].

A multiple, embedded case study design was thus carried out among seven projects to identify explanatory theories about what made a project successful in its given context and why. Cases were chosen based on the diversity of their components [28] [31] [32] [33], such as the profile of the case manager(s), the location (urban versus rural), the structural partnerships with general practitioners, the caseload per full-time equivalent (FTE) case manager, the systematic use of the results of a tool for making a comprehensive geriatric assessment (BelRAI, the InterRAI-HC instrument validated for Belgium [34] for making a care plan, the existence of an electronic patient record-or the absence of these characteristics. The choice was validated by a scientific steering committee, at the request of the NIHDI. Thematic content analysis and looking into the logic of the intervention as described by the project engineers within each project and constant comparison amongst projects allowed the identification and testing of the logic of the interventions in their own context [35]. This led to the further refinement of context-mechanisms-outcomes configurations explaining the success-or not-of the interventions in their contexts.

\subsection{Third Step: Identification of Mid-Range Theories in Literature}

In the meanwhile, a literature review was carried out to identify candidate mid-range theories likely to support the logic of the interventions. The process of this review is described in another paper, under submission [36]. These candidate theories were then confronted with the empirical data coming from the case studies and discussed within the group of researchers who helped to adjudicate between rival theories or, in some cases, to refine or expand existing theories in order to apply them to case management interventions under study.

\subsection{Fourth Step: Adjudication between Rival Theories or Refinement of Existing Theory}

Here again, iterative discussions with the members of the consortium involved in the data analysis provided insight into the theories capable of explaining the results coming out of the empirical analysis and the literature review. The findings of these discussions were then submitted to the civil servants of the NIHDI, case managers and project coordinators.

\section{Results}

\subsection{Programme Theory of the Interventions}

The logic of the interventions is described per case in the overall report [37]. Summarised, professional case management is expected to organise care in a meaningful way and anticipate the negative consequences of adverse events, such as a new illness or 
exacerbations, by the means of a structured, yet highly individualised approach including close monitoring of the care plan and the individual situation at home. To achieve this, the following activities were carried out: comprehensive standardised geriatric assessment at intake and at least every six months (more if the situation worsened), regular home visits, consultation and coordination meetings with healthcare providers involved, together with the older person and his informal caregiver, use of the results of the standardised assessment for making and prioritizing the goals of the care plan, follow-up and evaluation of this care plan by the means of a (preferably shared) patient record, use of (a) evidence-based and interdisciplinary agreed protocols and (b) Registry (list of beneficiaries of the projects)-including prompts for care plan implementation and finally, intervisions to discuss the activities of the case managers and the possible strategies for improvement. Finally, the type of case management provided should be linked to the profile of the beneficiary: the higher the dependency level (i.e. cognitive and functional), the higher the need for clinical case management. Reversed, frail older people whose functional impairment is lower than 3 on the ADL and 24 on IADL scale could in most cases manage their care on their own. Only if this is not possible, coordination of their care could be supported effectively by a coordinator from a coordination agency, such as GDT/SEL in the Dutch-speaking part of Belgium ("Geïntegreerde Dienst voor Thuiszorgverzorging/Samenwerkingsinitiatief Eerstelijnsgezondheidszorg”) or their French-speaking counterpart, CCSSD ("Centre de Coordination de Soins et de Services à Domicile"), who only coordinates the required care, without the intensity and means included in clinical case management [38]. In between those two extreme situations, social case management would be recommended, in which the case manager is most often a social worker and/or a psychologist.

\subsection{Confrontation with the Empirical Data}

During the four years of the evaluation, 4711 frail older people were included in the 22 case management projects. Their median age was 81 years ( 76 - 86); $68.2 \%$ were women and $53.1 \%$ lived alone. Among them, 17.5\% had a low level of deficiency (defined by having CPS and ADL scores below the cut-off of three on both scales), 35.18\% had a mean level of deficiency (defined as having ADL or CPS $\geq 3$ but no hospitalisation during the three months preceding the inclusion in the case management process) and 9, 78\% had a severe level of deficiency (defined as having a ADL or CPS $\geq 3$ and a hospitalisation during the three months preceding inclusion). Some features of the seven cases under study are shown in Table 1.

Table 1. Some features of the seven projects of the case studies.

\begin{tabular}{|c|c|c|c|c|c|c|c|}
\hline & Project 1 & Project 2 & Project 3 & Project 4 & Project 5 & Project 6 & Project 7 \\
\hline Social workers & Yes & & Yes & Yes & & Yes & \\
\hline
\end{tabular}


Continued

\begin{tabular}{|c|c|c|c|c|c|c|c|}
\hline Occupational therapists & & & Yes & & & Yes & \\
\hline Psychologists & & & & & Yes & Yes & \\
\hline Educators & Yes & & & & & & \\
\hline Area & Rural & Urban & Urban & Rural & Urban & Rural & Urban \\
\hline Region & German speaking & Flanders & Flanders & Flanders & Wallonia & Brussels & Flanders \\
\hline Use of the results of BelRAI for the care plan & No & Yes & Yes & No & No & No & Yes \\
\hline Use of an electronic health record & Yes & Yes & Yes & Yes & Yes & Yes & No \\
\hline
\end{tabular}

$\left.{ }^{*}\right)$ FTE $=$ full time equivalent.

\subsection{Identification of Theories in the Literature}

Firstly, we found an overall theory of the likely effectiveness of case management to help frail older people to stay at home, in the different levels of integration in the rainbow model of Valentijn et al., as is shown in Figure 1 [39].

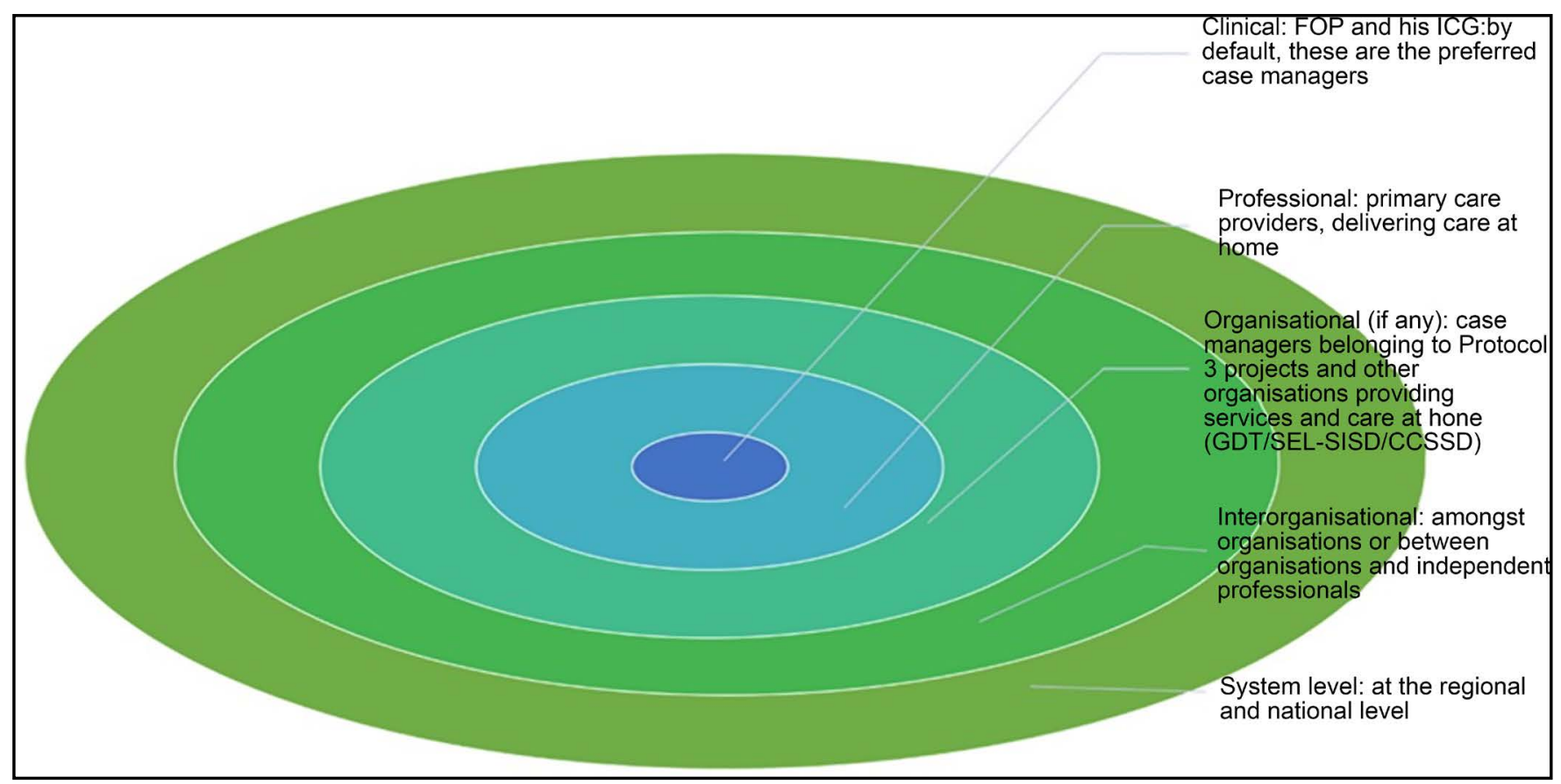

Figure 1. Situation of case management in Belgium within the different levels of care provision. (FOP: Frail Older person; ICG: Informal Caregiver; GDT: Geïntegreerde Dienst voor Thuiszorgverzorging; SEL: Samenwerkingsinitiatief Eerstelijnsgezondheidszorg; CCSSD: Centre de Coordination de Soins et de Services à Domicile).

The care is provided at the individual level, to the frail older people and their informal caregivers (if any), but in coherence with the care provided by primary care providers, which is consistent with the rules of their own organisations (the case management team and the umbrella organisation to which they belong), dependent of existing rules and conventions between organisations (if these exist) and their own corporations (e.g. 
nurse, psychologist, physician, social worker, etc.), in accordance with regional and national regulations and paid by NIHDI. Because of this, case management starts at the clinical level but transcends all levels.

Secondly, Wagner's Chronic Care Model was chosen as candidate theory, potentially capable to explain how the components of the interventions interacted with each other to lead to meaningful results for the older people receiving case management.

\subsection{Identification of Two Candidate Theories to Refine the Initial Programme Theory of the Interventions}

Context-mechanism-outcomes configurations (CMOCs) can be seen as mid-range theories. In this paper, the outcomes of the CMOC are presented from the users' perspective. Enabling contexts will trigger mechanisms leading to positive outcomes. Conversely, hindering contexts will not trigger them, leading to negative outcomes. These contexts can be elements from the inside or the outside of the interventions. Only the CMOCs of the two most frequently reported outcomes are presented in here.

The two main mid-range theories are that the frail older people are staying at home despite their frailty because they (1) feel capable of this and (2) they feel socially supported. Table 2 shows in which contexts and by which mechanisms these outcomes are made possible. Mainly, the resources needed by frail older people to trigger reasonings leading to the feeling of capability are linked to their initial status (=context). Findings suggested that the more severe the cognitive impairment, the more the need for clinical case management. Two examples are provided in Figure 2 and Figure 3.

Table 2. First mid-range theory: perception of the frail older person and his informal caregiver about having the capacity - are auto-determined to remain at home-or not.

\begin{tabular}{|c|c|c|c|}
\hline \multirow[t]{2}{*}{ CONTEXT } & \multicolumn{2}{|c|}{ MECHANISM } & \multirow[t]{2}{*}{ OUTCOMES } \\
\hline & RESOURCES & REASONING & \\
\hline $\begin{array}{l}\text { Having neither ADL } \\
\text { nor cognitive im- } \\
\text { pairments }\end{array}$ & $\begin{array}{l}\text { Care coordination } \\
\text { provided by a } \\
\text { coordination centre }\end{array}$ & $\begin{array}{l}\text { The focus is on facilitation } \\
\text { of the access to the care } \\
\text { and support needed. "If } \\
\text { any crisis situation } \\
\text { appears I am, or my } \\
\text { informal caregiver is, able } \\
\text { to call for adequate help." }\end{array}$ & $\begin{array}{l}\text { Feeling capable to } \\
\text { remain at home }\end{array}$ \\
\hline $\begin{array}{l}\text { Having only a low } \\
\text { impairment in ADL } \\
\text { (lowADLonly), }\end{array}$ & $\begin{array}{l}\text { Care coordination } \\
\text { provided by a } \\
\text { coordination centre }\end{array}$ & $\begin{array}{l}\text { In this situation also, the } \\
\text { focus is on facilitation, } \\
\text { especially through } \\
\text { adequate utilisation of } \\
\text { information by the frail } \\
\text { older person and his } \\
\text { informal caregiver }\end{array}$ & $\begin{array}{l}\text { Uncertainty about } \\
\text { feeling capable to } \\
\text { remain at home or not }\end{array}$ \\
\hline $\begin{array}{l}\text { Having a high level of } \\
\text { ADL impairment } \\
\text { (highADLonly) }\end{array}$ & $\begin{array}{l}\text { Social case } \\
\text { management }\end{array}$ & $\begin{array}{l}\text { Exacerbations and worsening } \\
\text { of the situation are anticipated } \\
\text { and prevented. }\end{array}$ & $\begin{array}{c}\text { Not feeling capable to } \\
\text { remain }\end{array}$ \\
\hline
\end{tabular}




\section{Continued}

Having a high level of cognitive impairment (highCPS)
Clinical case

management
Exacerbations and worsening

of the situation are anticipated

and prevented and, in most cases, cared of.

\subsubsection{First Mid-Range Theory: The Frail Older People Are Staying at Home Because They Feel Capable of It}

The first context where case management with a professional case manager is likely to affect the perceived capability of the frail older people to remain at home: older persons with a high level of functional impairment. In this case, social case management seems more relevant. Figure 2 shows the configuration of several mechanisms sitting within the CMOCs and can be seen as finer hypotheses about specific causal links and processes within them.

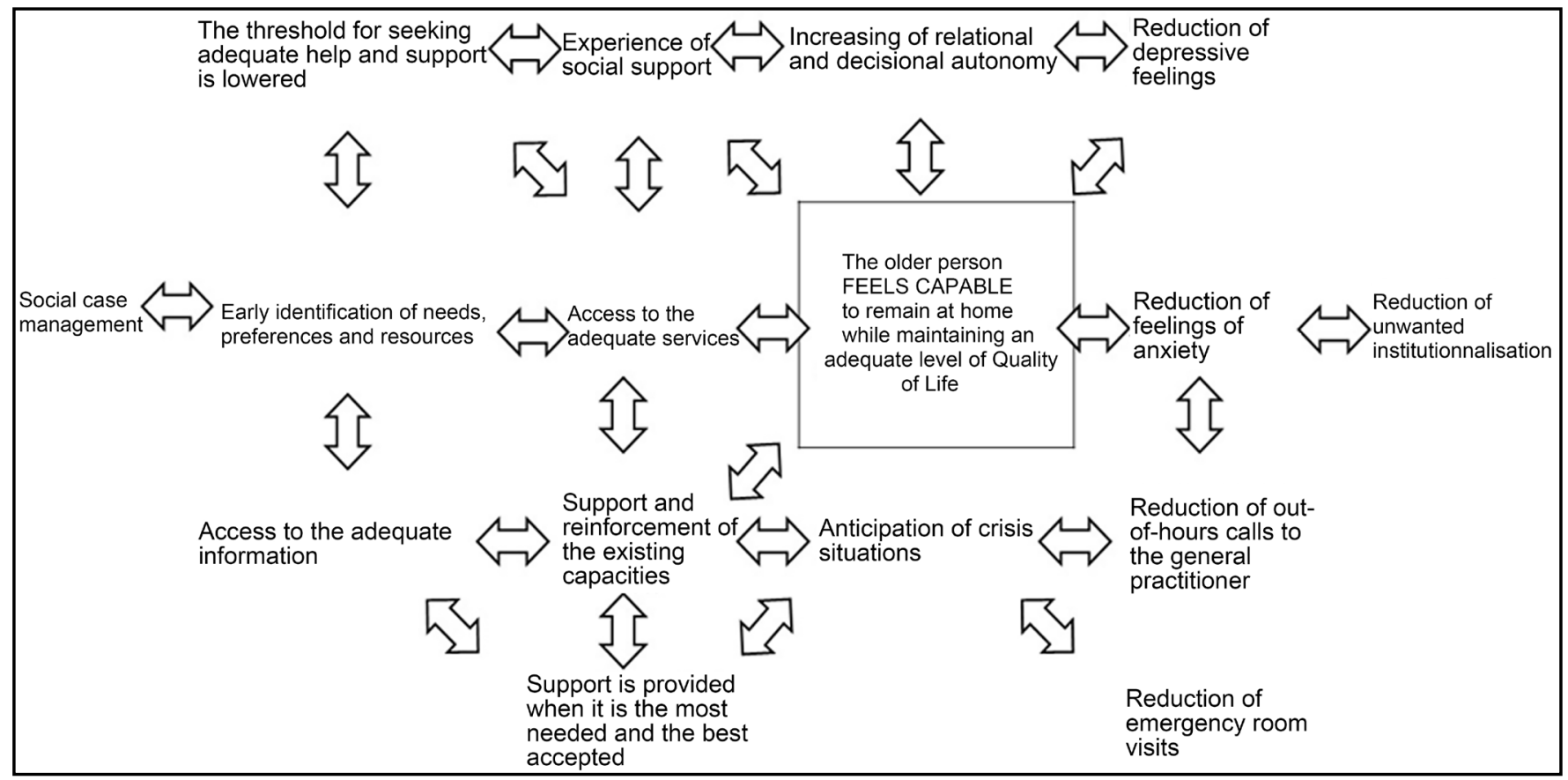

Figure 2. Likely effectiveness of social case management for frail older people (FOP) with a high level of functional impairment on their perceived capability to stay at home.

The second context is where a professional case manager is likely to affect the perceived capability of the frail older people to remain at home for older persons with a high level of cognitive impairment. Findings showed that older people with high cognitive impairment could not live at home without an informal caregiver and therefore, clinical case management for this population systematically concerned the older person-informal caregiver dyad. In comparison with Figure 2 reflecting social case management, changes appear in bold in Figure 3. 


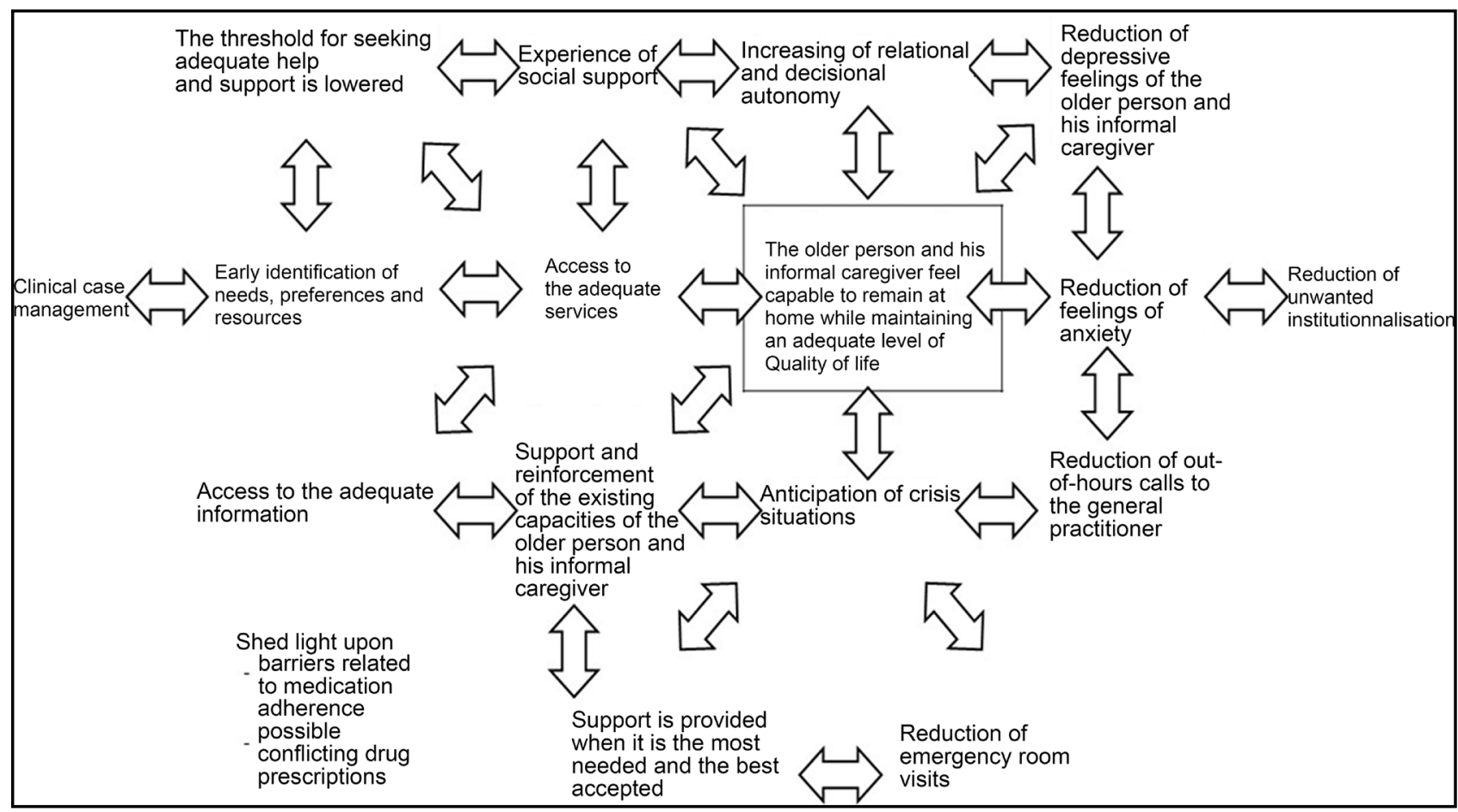

Figure 3. Likely effectiveness of clinical case management for frail older people and informal caregiver with a cognitive impairment on their perceived capability to stay at home.

However, case management can also trigger negative reactions, such as the perception by the beneficiaries that the care is too intrusive, including the care recommended by the case managers. "My home has become a renovated church, in which everyone can enter and I don't recognize it any more" (older person, benefiting from case management). This is the case with any type of case management, as is shown in Figure 4.

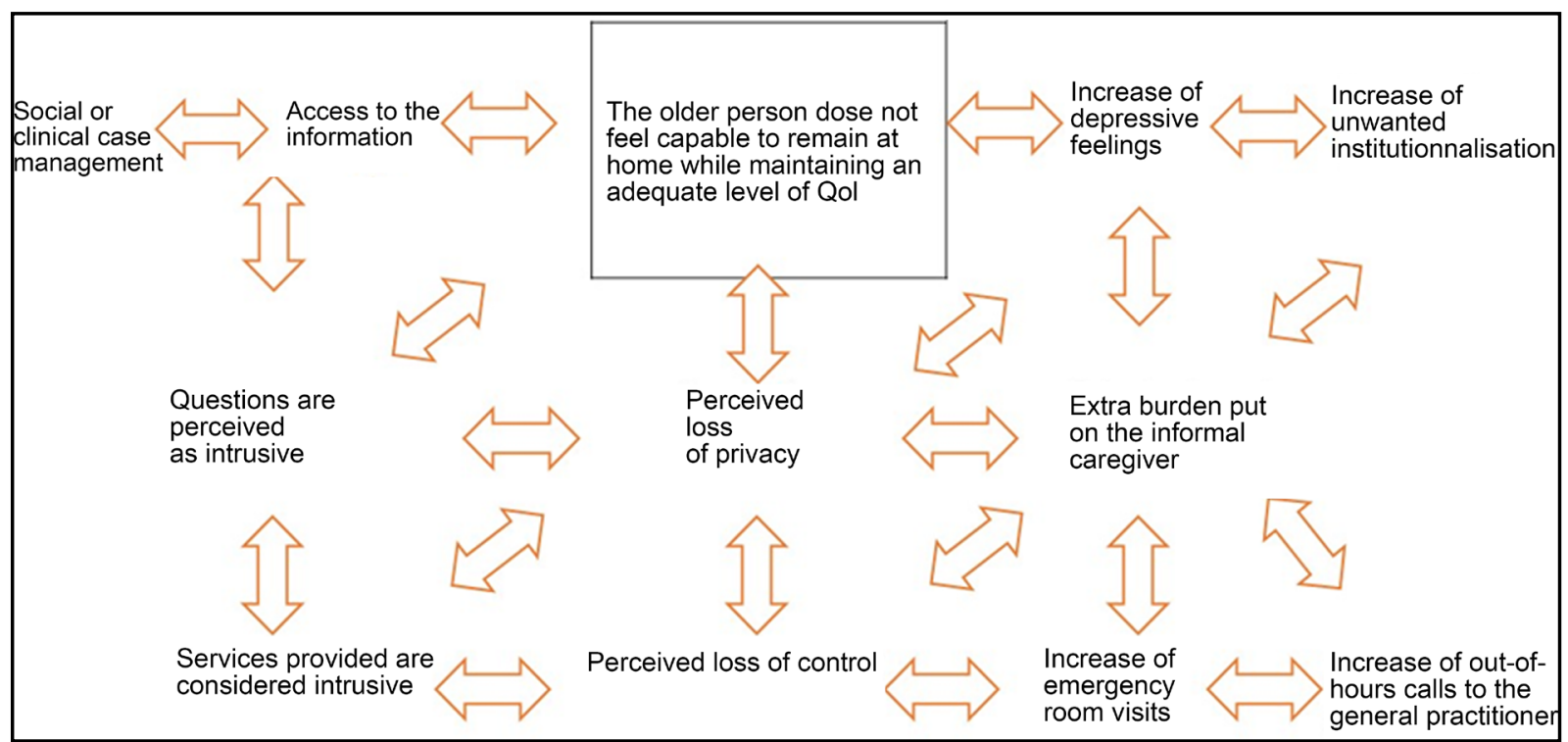

Figure 4. Risk of possible adverse effects of case management for frail older people having a high level of impairment regarding ADL. 


\subsubsection{Second Mid-Range Theory: The Frail Older People Are Staying at Home Because They Feel Socially Supported}

The second most cited intermediate outcome in the findings was related to the experienced social support. Four elements of the contexts were identified to trigger positive mechanisms in this domain: the access to adequate training for the case managers, physical accessibility of adequate day care centres, financial and physical access to the relevant services and an adequate caseload for the case managers (i.e. less than 40 beneficiaries simultaneously per full time equivalent case manager). In Figure 5, the interacting components are shown, starting with the case management providing by a professional having access to adequate training and leading to the outcome of perceived social support. These same mechanisms are triggered by the other contexts mentioned in Table 3, highlighting the importance of the accessibility of meaningful activities, often delivered in day care centres. Also, a caseload under 40 per full time equivalent case manager is essential because sufficient time is needed to identify significant others who can support these meaningful activities.

Table 3. Second mid-range theory: The frail older person can remain at home because he and his informal caregiver experience social support and feel they have a place in the community.

\begin{tabular}{|c|c|c|c|}
\hline \multirow[t]{2}{*}{ CONTEXT } & \multicolumn{2}{|c|}{ MECHANISMS } & \multirow{3}{*}{$\begin{array}{l}\text { OUTCOMES } \\
\text { The older person } \\
\text { experiences } \\
\text { social support }\end{array}$} \\
\hline & RESOURCES & REASONING & \\
\hline $\begin{array}{l}\text { Existing training } \\
\text { (including supervisions) } \\
\text { to enhance case } \\
\text { manager's skills }\end{array}$ & $\begin{array}{l}\text { The case manager has the skills to } \\
\text { recognise the signs of social } \\
\text { isolation, based on the } \\
\text { multidimensional geriatric } \\
\text { assessment and clinical judgment } \\
\text { during regular home visits. }\end{array}$ & $\begin{array}{l}\text { The older people and their } \\
\text { informal caregivers feel } \\
\text { recognized in their needs of } \\
\text { meaningful social contacts }\end{array}$ & \\
\hline $\begin{array}{l}\text { Physical accessibility of } \\
\text { adequate day care centres }\end{array}$ & $\begin{array}{l}\text { The case manager encourages } \\
\text { meaningful activities to the older } \\
\text { person, such as weekly visits to day } \\
\text { care centres }\end{array}$ & $\begin{array}{l}\text { The proposed activities } \\
\text { make sense to the frail older } \\
\text { people and their informal } \\
\text { caregivers } \\
\text { The proposed activities } \\
\text { induce a feeling of social } \\
\text { utility because of the } \\
\text { reciprocity of the social } \\
\text { interaction. }\end{array}$ & \\
\hline $\begin{array}{l}\text { Financial and } \\
\text { geographical accessibility } \\
\text { to services }\end{array}$ & $\begin{array}{l}\text { The case manager identifies } \\
\text { barriers to access the meaningful } \\
\text { activities and proposes services to } \\
\text { address them (financial, } \\
\text { geographical) }\end{array}$ & $\begin{array}{l}\text { The older people feel they } \\
\text { are able to access these } \\
\text { activities and anticipate they } \\
\text { can benefit from them } \\
\text { Observing peers with similar } \\
\text { conditions strengthen the } \\
\text { older people's and their } \\
\text { informal caregivers' belief } \\
\text { that they can succeed in } \\
\text { remaining at home }\end{array}$ & \\
\hline $\begin{array}{l}\text { Adequate caseload of the } \\
\text { case manager ( }<40 \text { frail } \\
\text { older person/FTE case } \\
\text { manager) allows for } \\
\text { sufficient time spent to } \\
\text { identify significant others }\end{array}$ & $\begin{array}{l}\text { The case manager identifies } \\
\text { significant others who can support } \\
\text { meaningful social interactions with } \\
\text { the frail older persons }\end{array}$ & $\begin{array}{l}\text { The older people and their } \\
\text { informal caregivers feel } \\
\text { socially and emotionally } \\
\text { supported by significant } \\
\text { others }\end{array}$ & $\begin{array}{l}\text { The older person } \\
\text { does not feel } \\
\text { supported } \\
\text { socially }\end{array}$ \\
\hline
\end{tabular}


Figure 5 shows the configuration of several mechanisms embedded within the CMOCs and, as done for the first mid-range theory, can be seen as finer hypotheses about specific causal links and processes within them.

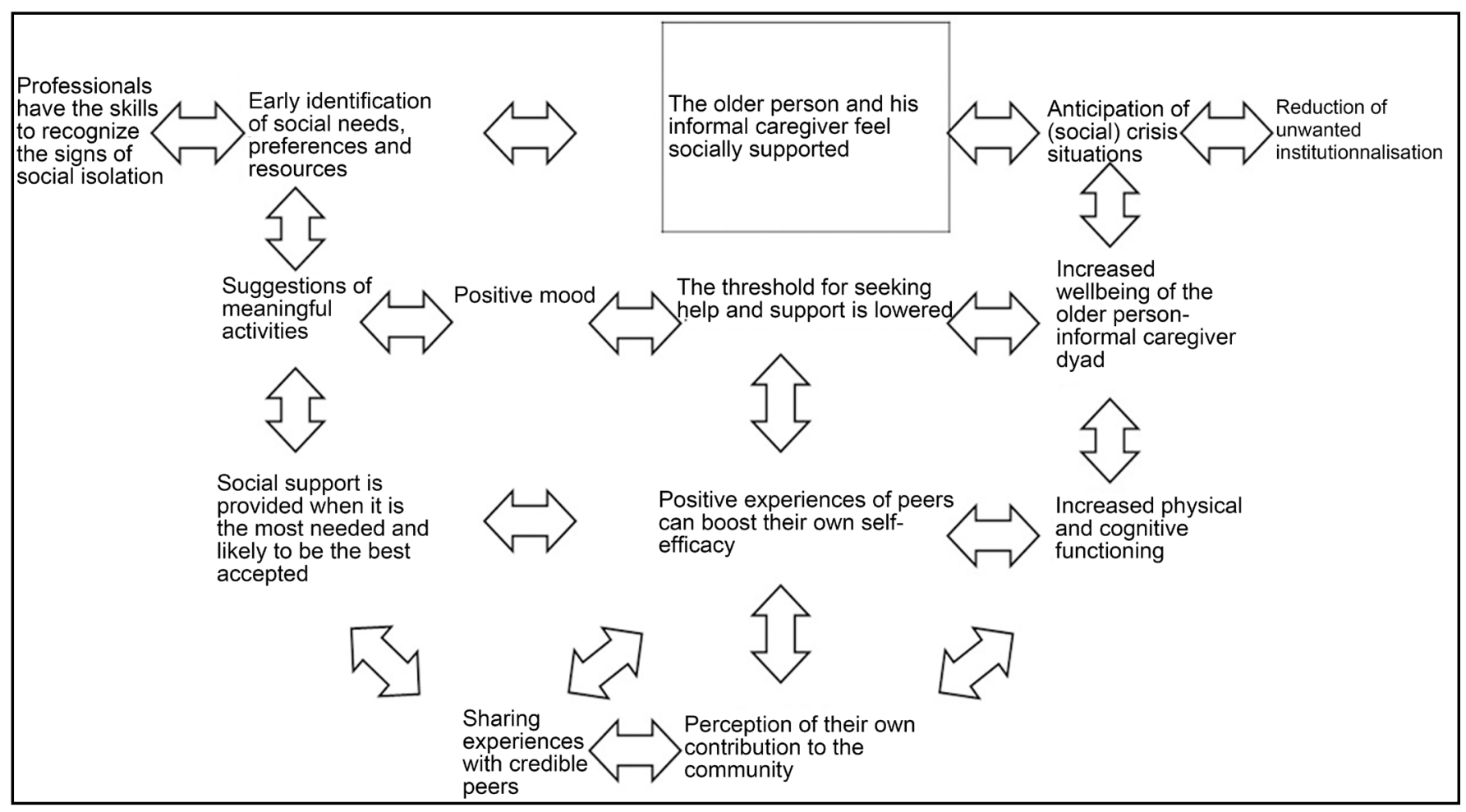

Figure 5. Likely effectiveness of case management providing by professionals having access to adequate training for older people with a cognitive impairment on their perception of social support.

\section{Discussion}

In this paper, we described how two mid-range theories could foster an adequate framework explaining how and why case management can be effective for frail community-dwelling older people with complex care needs and under what conditions.

First, the older person's perception of its own capability, along with the perception of the informal caregiver can lead to desired outcomes because they can influence the choice of activities (e.g. accepting the services and care offered) and the belief in possible success (remaining at home). It can also influence coping efforts once they are initiated. This is very close to the self-efficacy beliefs of Bandura [40]. Indeed, these efficacy expectations will modulate how much effort will be needed by frail older people and their informal caregivers and how long they will persist to face the difficulties inherent to their complex care needs. Even small adverse events, such as a phone failure, can lead to chain reactions of negative events, leading in turn to self-debilitating expectations (as opposed to self-efficacy beliefs) and feelings of helplessness. This capability can be successfully supported by an adequate type of case management, as severely cognitively impaired frail older people are more likely to be helped by clinical case management, in which case the intervention also encompasses support to medication 
adherence and a strong focus on the capabilities and needs of the informal caregiver.

Second, perceived social support identified as a mediator for helping frail older people to stay at home. This can be successfully influenced by the skills of the case manager, who should have access to adequate training and sufficient time to fulfil this important function. Moreover, there is also a need for access to meaningful activities, which in turn can support the need for the feeling of belonging to a community, by learning from each other's shared experiences and contributing to others. This notion of reciprocity in care is absolutely crucial, and can be seen as a "manifestation of mutual respect, which recognises that there is the potential for virtually all kinds of caring relationship to be of mutual benefit" [41].

This does not imply that capability and perceived social support are the only determinants of desirable outcomes for this population. Other skills and resources are also important. However, this analysis showed that beliefs about capability and social support can be an important part of older people's actions and decisions, such as the acceptance of services or activities, how much effort they will expend and how long they will sustain the effort in dealing with the stressful situation inherent to living at home during the old age with complex care needs.

To support these outcomes, some contextual elements are shown to be important. First, there is the crucial point of the identification of the correct beneficiaries, in order to support their care with the adequate level of management. Our results have shown that beneficiaries having neither ADL nor cognitive impairments nor a low level of ADL impairments can sufficiently be supported by coordinators, hired by coordination centres, such as GDT/SEL or CCSSD and do not need the input of professional case managers. Conversely, beneficiaries with a high level of ADL impairment could adequately be helped by a more social type of case management, while beneficiaries having a high level of cognitive impairment need clinical case management. Therefore, careful assessment of the situation, which can evolve rapidly in this population, should be assessed and monitored constantly by primary care providers, if not by the case managers themselves. Second, case managers should be aware that their intervention is also likely to lead to adverse outcomes and take actions to prevent these and, if needed, address them timely. Third, case managers and care coordinators should have access to adequate training in order to provide them with the skills to function as case managers and be able to, among other skills, recognize the situations of social isolation. This is an issue in Belgium, where no specific training for case managers is organised. Part of these skills could be acquired through continuous professional development or service-based training, especially if these are supported by cross-training of health professionals through multidisciplinary education opportunities [42]. Fourth, access to the recommended services should be made possible in a timely manner, especially access day care centres, which can act as an important starting point to (re)connect beneficiaries to their social network, while offering them the opportunity to conduct meaningful activities. Unfortunately, these centres currently have long waiting lists despite their efforts to open their services to as much beneficiaries as possible, e.g. by admitting beneficiaries with cognitive problems immediately, even for only one day per week, while the 
average frequentation is three times a week. Furthermore, some regions in Belgium do not have such day care centres (e.g. in German-speaking Belgium). In this study, we only acknowledged the importance of these centres because of the social-related outcome but other studies have shown the benefits of these centres on the burden of the informal caregiver, especially in patients with cognitive impairment [43]. Finally, case managers should have a caseload that does not exceed 40 frail older people-as defined in our study-per full time equivalent case manager. Indeed, the constant monitoring of the situation, directly or by the means of primary care providers who are already in contact with their patient on a daily basis [44]. The latter are also called "sentinel" professionals, who can contact the case manager immediately in case of need of their intervention. This is important to be able to follow-up the situation of the patient on a social level, but of course also on the biomedical and psychological level.

The iterative four-stepped approach recommended by Pawson et al. proved very useful to identify and refine two mid-range theories likely to explain why, how and for whom case management could be effective for this population. The strength of this method lays in the possibility to zoom in on context-and-outcome-related mechanism in a highly structured way to unveil explanations about why case management can lead to desired outcomes. The weakness is closely related to this strength. Indeed, because of time constraints, we were only able to unveil a part of the process, i.e. those related to the most cited outcomes. This is the case for most of the realist evaluations, can be most frustrating, has to be seen as work-in-progress and calls for further research to unveil the other CMOC in this area [27]. However incomplete, the approach used to identify and refine mid-range theories can be of use for evaluation teams of other bottom-up projects.

Study limitations include the indirect report of the perspective on frail older people, as perceived by the care providers included in the case management projects, as we did neither collect data directly from the beneficiaries of case management nor from their informal caregivers. These results will be confronted when the second part of the evaluation will be carried out, as the evaluation is still ongoing. For this, we plan to interview dyads of older people benefiting from case management and their informal caregivers, along with other care providers at the primary care level, in order to include their point of view on what is it about case management that causes desirable outcomes, for which frail older people, under which conditions and why.

\section{Conclusions}

As a result of a realist evaluation of case management's effectiveness to yield desirable outcomes for frail, community-dwelling older people, we used the capability and perceived social support framework as a mid-range theory. Unlike systematic reviews including solely experimental designs, this approach enabled us to explain that case management is likely to foster positive outcomes if the type of case management is focused on the capability and the perceived social support of the beneficiaries. It should be able to guide professionals, teachers and case management supervisors to strengthen case 
management teams and individual case managers' skills to support beneficiaries' beliefs about their own capabilities and perceived social support, as an important means to help them to remain at home in good conditions for as long as they wish.

\section{Funding Acknowledgements}

This work was supported by the Belgian National Institute of Health and Disability Insurance (NIHDI).

\section{References}

[1] van Kempen, J.A.L., et al. (2014) Construct Validity and Reliability of a Two-Step Tool for the Identification of Frail Older People in Primary Care. Journal of Clinical Epidemiology, 67, 176-183. http://dx.doi.org/10.1016/j.jclinepi.2013.08.008

[2] Paulus, D.v.d.H., K. and Mertens, R. (2012) Chronic Care in Belgium: Development of a Position Paper. Belgian Healthcare Knowledge Centre (KCE), Brussels.

https://kce.fgov.be/publication/report/position-paper-organisation-of-care-for-chronic-pati ents-in-belgium\#.V tNvFSLSt8

[3] Leichsenring, K., Billings, J. and Nies, H. (2013) Long-Term Care in Europe: Improving Policy and Practice. Palgrave Macmillan, Basingstoke, 1-416.

[4] Goodwin, N. (2013) Understanding Integrated Care: A Complex Process, a Fundamental Principle. International Journal of Integrated Care, 13, . http://dx.doi.org/10.5334/ijic.1144

[5] Lloyd, J.W. (2005) Suzanne, Integrated Care: A Guide for Policy Makers, in Alliance for Health and the Future.

http://www.ilcuk.org.uk/images/uploads/publication-pdfs/pdf pdf 7.pdf

[6] National Collaboration for Integrated Care and Support (2013) Our Shared Commitment. National Collaboration for Integrated Care and Support. https://www.gov.uk/government/publications/integrated-care

[7] Wagner, E.H., Austin, B.T. and Von Korff, M. (1996) Organizing Care for Patients with Chronic Illness. Milbank Quarterly, 74, 511-544. http://dx.doi.org/10.2307/3350391

[8] Vlayen J, V.D.W.G., Camberlin, C., Paulus, D., Leys, M. and Ramaekers, D. (2006) Clinical Quality Indicators. Belgian Healthcare Knowledge Centre (KCE), Brussels.

[9] ElZarrad, M.K., Eckstein, E.T. and Glasgow, R.E. (2013) Applying Chronic Illness Care, Implementation Science, and Self-Management Support to HIV. American Journal of Preventive Medicine, 44, S99-S107. http://dx.doi.org/10.1016/j.amepre.2012.09.046

[10] Nolte, E. and McKee, M. (2008) Caring for People with Chronic Conditions: A Health System Perspective (European Observatory on Health Systems and Policies). European Observatory on Health Systems Policies Series. Vol. 1, Open University Press, Maidenhead.

[11] CMSA -Case Management Society of America (2011) Definition of Case Management. http://www.cmsa.org/PolicyMaker/ResourceKit/AboutCaseManagers/tabid/141/Default.aspx

[12] AHRQ (2013) Outpatient Case Management for Adults with Medical Illnesses and Complex Care Needs, R.Q. Agency for Healthcare, Editor.

[13] Bernabei, R., Onder, G. and Landi, F. (2010) Comprehensive Care for Older Adults: Case Management Approach. Journal of the American Geriatrics Society, 58, 1202-1203. http://dx.doi.org/10.1111/j.1532-5415.2010.02884.x

[14] May, C.R., Eton, D.T., Boehmer, K., Gallacher, K., Hunt, K., MacDonald, S., et al. (2014) Rethinking the Patient: Using Burden of Treatment Theory to Understand the Changing 
Dynamics of Illness. BMC Health Services Research, 14, 281.

http://dx.doi.org/10.1186/1472-6963-14-281

[15] Barbic, S., Mayo, N.E., White, C.L. and Bartlett, S.J. (2014) Emotional Vitality in Family Caregivers: Content Validation of a Theoretical Framework. Quality of Life Research, 23, 2865-2872. http://dx.doi.org/10.1007/s11136-014-0718-4

[16] Lamont, T., Barber, N., de Pury, J., Fulop, N., Garfield-Birkbeck, S., Lilford, R., et al. (2016) New Approaches to Evaluating Complex Health and Care Systems. BMJ, 352, i154. http://dx.doi.org/10.1136/bmj.i154

[17] Pawson, R. (2012) Evidence-Based Policy: A Realist Perspective. Sage Publication, London.

[18] Mitchell, M. (2011) Complexity: A Guided Tour. Oxford University Press, New York, 368.

[19] Greenhalgh, T., Kristjansson, E. and Robinson, V. (2007) Realist Review to Understand the Efficacy of School Feeding Programmes. BMJ, 335, 858-861.

http://dx.doi.org/10.1136/bmj.39359.525174.AD

[20] Punton, M. (2016) Reflections from a Realist Evaluation in Progress: Scaling Ladders and Stitching Theory. IDS Bulletin, 18, 12.

[21] Wong, G., Greenhalgh, T., Westhorp, G., Buckingham, J. and Pawson, R. (2013) RAMESES Publication Standards: Realist Syntheses. BMC Medicine, 11, 21. http://dx.doi.org/10.1186/1741-7015-11-21

[22] Wong, G., Westhorp, G., Manzano, A., Greenhalgh, J., Jagosh, J. and Greenhalgh, T. (2016) RAMESES II Reporting Standards for Realist Evaluations. BMC Medicine, 14, 96. http://dx.doi.org/10.1186/s12916-016-0643-1

[23] Rolfson, D.B., Majumdar, S.R., Tsuyuki, R.T., Tahir, A. and Rockwood, K. (2006) Validity and Reliability of the Edmonton Frail Scale. Age and Ageing, 35, 526-529. http://dx.doi.org/10.1093/ageing/afl041

[24] Buntinx, F., Paquay, L., Fontaine, O., Ylieff, M. and De Lepeleire, J. (2004) Options for a New Procedure for Determining Care Needs in Belgium: An Initial Exploration. Archives of Public Health, 62, 173-184.

[25] de Almeida Mello, J., Van Durme, T., Macq, J. and Declercq, A. (2012) Interventions to Delay Institutionalization of Frail Older Persons: Design of a Longitudinal Study in the Home Care Setting. BMC Public Health, 12, 615. http://dx.doi.org/10.1186/1471-2458-12-615

[26] Wong, G., Greenhalgh, T. and Pawson, R. (2010) Internet-Based Medical Education: A Realist Review of What Works, for Whom and in What Circumstances. BMC Medical Education, 10, 12. http://dx.doi.org/10.1186/1472-6920-10-12

[27] Wong, G., Greenhalgh, T., Westhorp, G. and Pawson, R. (2012) Realist Methods in Medical Education Research: What Are They and What Can They Contribute? Medical Education, 46, 89-96. http://dx.doi.org/10.1111/j.1365-2923.2011.04045.x

[28] George, A. and A. Bennett (2005) Case Studies and Theory Development in the Social Sciences. MIT Press, Cambridge, MA.

[29] Pawson, R., Tilley, N. (2013) Realistic Evaluation. Sage, London.

[30] Collier, D. (2011) Understanding Process Tracing. PS: Political Science and Politics, 44, 823-830.

[31] Eisenhardt, K. (1989) Building Theories from Case Study Research. The Academy of Management Review, 14, 532-550.

[32] Gerring, J. (2007) Case Study Research: Principles and Practices. Cambridge University Press, Cambridge. 
[33] Yin, R. (2009) Case Study Research: Design and Methods. Sage, Thousand Oaks.

[34] InterRAI (2016) Instruments: An Overview of the InterRAI Suite. http://interrai.org/instruments.html

[35] Rycroft-Malone, J., et al. (2012) Realist Synthesis: Illustrating the Method for Implementation Research. Implementation Science, 7, 33. http://dx.doi.org/10.1186/1748-5908-7-33

[36] Van Durme, T., Billings, J., Cès, S., Schmitz, O. and Macq, J. (2016) A Realist Synthesis of Case Management for Community-Dwelling Older People: An Overview. The 2nd International Conference on Realist Evaluation and Synthesis: Strengthening Principles, Advancing Practice, London.

[37] Van Durme, T., Schmitz, O., Maggi, P., Delye, S., Gosset, C., Lopez-Hartmann, M., Remmen, R. and Macq, J. (2014) Scientific Evaluation of Projects of Alternative Forms of Care or Support of Care for Frail Elderly, in Order to Allow Them to Maintain Their Autonomy and to Live Independently in Their Homes: "Protocol 3"-Contextual Description of Projects' Components and Implementation Analysis. National Institute of Health and Disability Insurance, Brussels, 320.

[38] Van Durme, T., et al. (2015) A Comprehensive Grid to Evaluate Case Management's Expected Effectiveness for Community-Dwelling Frail Older People: Results from a Multiple, Embedded Case Study. BMC Geriatrics, 15, 67. http://dx.doi.org/10.1186/s12877-015-0069-1

[39] Valentijn, P.P., Schepman, S.M., Opheij, W. and Bruijnzeels, M.A. (2013) Understanding Integrated Care: A Comprehensive Conceptual Framework Based on the Integrative Functions of Primary Care. International Journal of Integrated Care, 13, e010. http://dx.doi.org/10.5334/ijic.886

[40] Bandura, A. (1977) Self-Efficacy: Toward a Unifying Theory of Behavioral Change. Psychological Review, 84, 191-215. http://dx.doi.org/10.1037/0033-295X.84.2.191

[41] Draper, H. (2014) Care, Reciprocity and Being Valued. B.P. Commission, Birmingham.

[42] Langins, M. and Borgermans, L. (2015) Strengthening a Competent Health Workforce for the Provision of Coordinated/Integrated Health Services. Working Document, WHO.

[43] Mello, J.A., Macq, J., Van Durme, T., Cès, S., Spruytte, N., Van Audenhove, C. and Declercq, A. (2016) The Determinants of Informal Caregivers' Burden in the Care of Frail Older Persons: A Dynamic and Role-Related Perspective. Aging \& Mental Health, 1-6. http://dx.doi.org/10.1080/13607863.2016.1168360

[44] Somme, D., Trouve, H., Dramé, M., Gagnon, D., Couturier, Y. and Saint-Jean, O. (2012) Analysis of Case Management Programs for Patients with Dementia: A Systematic Review. Alzheimer's \& Dementia, 8, 426-436. http://dx.doi.org/10.1016/j.jalz.2011.06.004 
Submit or recommend next manuscript to SCIRP and we will provide best service for you:

Accepting pre-submission inquiries through Email, Facebook, LinkedIn, Twitter, etc. A wide selection of journals (inclusive of 9 subjects, more than 200 journals)

Providing 24-hour high-quality service

User-friendly online submission system

Fair and swift peer-review system

Efficient typesetting and proofreading procedure

Display of the result of downloads and visits, as well as the number of cited articles

Maximum dissemination of your research work

Submit your manuscript at: http://papersubmission.scirp.org/

Or contact ojn@scirp.org 